HIV AND ASSISTED REPRODUCTIVE TECHNOLOGIES

\title{
The physician as an accessory in the parental project of HIV positive people
}

\section{G Pennings}

J Med Ethics 2003;29:321-324

The question of the moral acceptability of infertility treatment to HIV positive persons raises a number of interesting ethical points regarding the responsibility of the infertility specialist for the outcome of his or her actions. The analysis of the physician's responsibility is conducted within the framework of accomplice liability. The physician is a collaborator in the parental project of the principals that is, the intentional parents. Both causal contribution and intention are considered as elements of complicity. It is concluded that a two per cent risk of vertical transmission when the woman is HIV positive is insufficient to blame the infertility specialist who helps her to conceive. Helping an infertile HIV positive infertile couple to have a child does not constitute reckless behaviour. When the couple is fertile, infertility treatment is directed at risk reduction and falls under the physician's obligation to act in the best interests of his patients.

Correspondence to: Guido Pennings, PhD, Free University Brussels, Department of Philosophy, Pleinlaan 2, room $5 \mathrm{C}$ 442, B-1050 Brussels, Belgium; gpenning@vub.ac.be

Accepted for publication 3 December 2002
W hen the first IVF babies were born, the infertility specialists proudly showed them to the world. By taking credit for bringing these children into the world, they indicated that they had a significant if not necessary part in the process. If this is correct, they should also take the blame when things go wrong. Although medically assisted reproduction has been practised for several decades, relatively little attention has been paid to the responsibility of the doctor. To what extent does the physician have the right to limit access to infertility treatment on the basis of health risks for the child? How is the responsibility divided between the physician and the parents? These questions have been raised sporadically in the context of infertility treatment to people at high genetic risk. This problem became a real issue, however, probably because of the special nature of the disease, when it was proposed that medical assistance be offered to HIV people needing help to reproduce. The situation is presented as a conflict between the right to procreate of the parents and concern for the welfare of the future child, the implication being that parents do not have the best interests of their child in mind and that the physician should protect the wellbeing of the child against its parents. Parents and physician are presented as opponents while the essence of their relationship lies in their partnership or collaboration.

\section{EVALUATING THE RISK}

There is little discussion of the magnitude of AIDS. Children who are infected with HIV before or at birth have a high chance of developing AIDS within the first year of life and of dying shortly afterwards. Those who survive into older childhood will develop progressively more complex health problems which will end with death in early adolescence. ${ }^{1}$ Although the highly active antiretroviral therapy (HAART) has improved their prospects considerably, their greatly reduced life expectancy and the impact of their failing health on the quality of their life makes it difficult to argue that these children have a reasonably happy life. ${ }^{2}$

The severity of the disease must be combined with the probability that it will occur. When the male partner is seropositive, the risk of infecting his partner and indirectly the offspring is very low when all precautions are taken. While the risk is practically eliminated in the case of an infected male, the vertical transmission rate with a seropositive woman is estimated between 1 and 2 per cent even when all prophylactic steps are taken. ${ }^{3}$ The harm principle applied to the context of reproductive responsibility states that "the greater the magnitude and probability of the predicted harm, the less justifiable it is to have children". ${ }^{4}$ Since the seriousness of AIDS is great, the probability of having an infected child should be low. A major problem when assessing this risk is that reasonable people disagree on the acceptable level of risk.

In general, people are responsible for what they do and for the consequences of what they do. An infertility specialist who helps a couple to conceive is responsible for the welfare of the child that will be born. This responsibility is obviously limited to foreseen and foreseeable consequences. Statistical information of a reliable nature enables both parents and physicians to foresee possible consequences. For instance, the base rate of major malformations in the general population is between 3 and 5 per cent; 3 to 5 per cent of all children have a major handicap. Although the debate on the possible negative effects of specific methods such as intracytoplasmic sperm injection (ICSI) is still going on, large follow up studies indicate that the malformation rate after assisted reproduction is not significantly different from natural conception. Consequently, the physician who helps people to conceive is responsible for the birth of children with handicaps and diseases since he knows the base rate. Although the physician is partially responsible as a collaborator, however, this does not imply that he is to be blamed. 
Whether he should be blamed depends on the analysis of his actions. To avoid confusion, the doctor is not responsible for the disease or for the infection itself but he is responsible for acting in a way which caused the conception and birth of a child that is affected. On this point, the situation resembles the standard wrongful life claim.

The attribution of responsibility is rendered problematic by the probabilistic nature of the information. The physician is not able to predict whether the child of a specific seropositive couple will be HIV infected. Contrary to many genetic diseases, he cannot rely on prenatal diagnosis to obtain certainty about the health status of the future child. Given the uncertainty regarding the health status of a specific future child, the issue of responsibility should be focused on the question of recklessness. Is the physician who knows that two per cent of the children will be infected guilty of recklessness? Recklessness is defined as conscious and unjustified risk taking. ${ }^{5}$ No ethical (or legal) theory is sufficiently developed to indicate a clear and rationally determined cut off point by which to distinguish reckless from justified risk taking. ${ }^{6}$ Nevertheless, the base rate of major malformations in the general population gives an indication of the minimally acceptable risk. People are not condemned or blamed for having children despite the five per cent risk of a serious handicap or disease. And neither is the infertility specialist blamed for participating in the conception of these children. Starting from this figure, the two per cent additional risk of HIV positive persons seems insufficient to talk of reckless behaviour. Moreover, if this percentage were considered sufficient, other categories of patients should also be excluded from infertility treatment. The probability of having a child with chromosomal abnormalities in women over 38 for instance exceeds the probability of perinatal infection in HIV positive women. ${ }^{\text {? }}$

\section{STANDARDS OF ACCEPTABILITY}

A possible source of conflict when two parties collaborate in a common project is the presence of different standards of acceptability. Parents and physician may have different views on responsible parenthood. These conceptions are (among other things) expressed in their attitude toward risk taking. Several authors have pointed out the discrepancy between the standard adopted by the parents and the standard applied by the physician, including J Glover, author of the Glover report on reproductive technologies to the European Commission. ${ }^{89}$ Some people seem to believe, however, that different standards exist for parents and physicians. The physician can (or must) apply a higher standard. But this is a mistake. It is not because physicians sometimes use higher standards and accept less risk than the parents (we would not notice when doctors accept higher risks since this simply results in the acceptance of the patient's request) but that they are bound by stricter rules. Parents are not allowed to take higher risks with the welfare of the future child than the physicians because they assume the final responsibility for the child.

The physician takes up the role of an accessory to, or collaborator with, the parents who are the principals. He has to decide whether to assist the parents to realise their reproductive goal. Since he contributes to the outcome of the treatment as a causal agent, he is accountable for the result. He must make a normative judgment about the rightness of his own participation and about the acceptability of the goal of the principals to which he contributes. ${ }^{10}$ He freely and deliberately engages as a moral agent and thus cannot hide behind the requesting parents. In other words, he cannot consider himself as a "technical agent" who merely performs actions which are parts of the plan of the couple. ${ }^{11}$ Health professionals who provide treatment services to initiate a pregnancy have special ethical responsibilities for the outcome. $^{12}$

The difference between medically assisted reproduction and natural procreation for the attribution of responsibility lies firstly in the active contribution of the physician and secondly in the possibility of intervention and control. When a couple is fertile, they do not need help from anyone to realise their wish to have a child. It would require a major violation of their autonomy and a massive intrusion into their private lives to prevent them from procreating. When they are infertile, society (in the person of the infertility specialist) is a necessary participant and can stop them from reproducing by refusing cooperation. If it is morally unacceptable for parents to embark on a parental project when there is a two per cent risk that the child will be HIV infected, society has the right to refuse help. Within the context of accomplice liability, the physician as a collaborator can only be wrong if the parental project of the principals is wrong. He cannot be blamed for helping in an acceptable or worthwhile plan. Within this context, room should be left for the personal conscience of the physician. Nevertheless, taking into account his obligations towards society, he should justify his refusal to help people whose request is considered acceptable by the professional community or by society at large.

\section{ACTS, CAUSATION, AND COMPLICITY}

Two major factors determine complicity: causation and intention. I will start with causation. Any act, however small, that contributes to the realisation of the goal makes the physician an accomplice. ${ }^{13}$ In real life, however, a selection of the causally contributing factors is made for the purpose of assigning responsibility (and blame) for the event. ${ }^{14}$ Which criteria can be used to distinguish acts that imply complicity from those that do not? Is a secretary who types a letter to make an appointment for an abortion collaborating in the abortion? Is the physician who teaches a seropositive woman to self inseminate an accessory to the conception and birth of the child? According to some, the responsibility of the physician can be diminished by restricting his active participation in the treatment. ${ }^{15}$ Instead of treating HIV positive people like normal infertility patients, the physician removes himself from the parental project by putting the patients between himself and the acts which constitute the treatment itself. He does not inseminate the woman, he merely teaches her how to inseminate herself. This solution partially relies on the idea that inserting the patients as autonomous persons into the causal chain after the contribution of the physician removes his responsibility. The physician can assist in a number of preliminary steps of the treatment but will stop short of full blown treatment. He could offer non-invasive investigations to exclude the most obvious causes of infertility, he could determine the fertile window or even wash the sperm that is later used for self insemination. ${ }^{16}$ Some believe that this is a distinction without a difference in kind. ${ }^{17}$ Providing information and doing preliminary examinations are all acts performed by the physician which contribute to the pregnancy. Nevertheless, as I will argue further, he can claim that his actions are not directed at the establishment of a pregnancy but at the reduction of the risk of infection, even when the risk is reduced precisely by increasing the woman's chances of becoming pregnant.

A point of discussion in the literature on responsibility is the effect of an autonomous decision in the chain of causation. According to some, the chain of responsibility is interrupted by a decision of an autonomous person. "Volitional actions cannot be said to be caused" (BMA, ${ }^{12}$ p 292). One of the components of the voluntary intervention principle of Hart and Honoré is that "when an intervening 
cause is a free and deliberate (fully voluntary) human action then it cancels the causal connection that would otherwise hold between an earlier causal factor and the harm" (Kadish $S_{,}^{13} \mathrm{p} \mathrm{123)}$. From that point onwards, the responsibility of the second person counts. This principle would have far reaching consequences for the responsibility of the physician. Consider a couple who request prenatal diagnosis and the test turns out positive. They decide to terminate the pregnancy. The couple would not have terminated the pregnancy if they had not received the information about the genetic condition of the fetus from the gynaecologist. This significant contribution turns the gynaecologist into an accomplice to the abortion. Conversely, gynaecologists who are opposed to abortion argue that the abortion is not the responsibility of the gynaecologist but of the parents. ${ }^{18}$ The parents could decide to have the child after receiving the information. In the discussion on sex selection, however, some authors propose to withhold information on the sex of the child to avoid an abortion for sexist reasons. ${ }^{19}$ Apparently, providing information on the sex of the fetus turns the physician into an accomplice when the parents terminate the pregnancy but telling the parents about the presence of a genetic disease does not. If an act or decision of the patients breaks the causal chain, the infertility specialist could participate in the reproduction of HIV positive people without becoming responsible as long as he does not perform the final part of the causal sequence. In light of the ongoing debate, however, the impact of an intervening intentional decision in the causal chain surely needs further clarification. ${ }^{20}$

\section{THE INTENTIONAL COMPONENT}

Two positions can be taken regarding the importance of intention for responsibility: it can be claimed that intention is necessary for blameworthiness or that foresight is sufficient. According to the former, a person is only liable as an accomplice when he has the intention to help the principals to reach their goal. The crucial factor for the determination of the physician's intention to help the principals is the fertility or infertility of the patients. If the couple are (assumed to be) infertile, his participation is necessary to reach the goal. Since the risks are zero if he refuses, the only motive the physician can have for helping the couple is to establish a pregnancy. With this intention, the doctor shares the project in the sense that he wants the couple to become pregnant. He is responsible for the welfare of the children born but he should not be blamed when an affected child is born since the risk is not so high that reasonable people would avoid it. When the couple are (assumed to be) fertile, his contribution is superfluous as far as the project of the parents is concerned. They do not need medical assistance to conceive. Given these considerations, the main intention of the physician is risk reduction. The physician can justify his active contribution by referring to his duty to minimise harm to his patients: the transmission risk after his participation is reduced compared to the risk of unprotected sex. The total responsibility for the risk to the child belongs to the parents since this risk is generated by their decision to procreate. The physician who helps the HIV positive fertile couple will be positively responsible for the reduction of the risk (which directly results from his contribution) but the remaining risk stays on the parents' account. The children who will be born HIV infected despite his efforts to reduce the risk are the direct responsibility of the parents. In part, this reasoning is based on the fact that the physician contributes to the conception only in the sense that his actions are part of the process. His contribution is superfluous since conception would also have taken place without him. As far as the parental plan is concerned, his participation is insignificant and negligible.

\section{RISK REDUCTION AND NEGATIVE RESPONSIBILITY}

The harm reduction mentioned above is linked to an interesting aspect of responsibility. A doctor who refuses to help an HIV infected couple is also responsible for the consequences of this decision. ${ }^{21}$ A person is negatively responsible for the occurrence of a state of affairs when that state of affairs obtains because an agent did not do something. ${ }^{22}$ Williams defines this type of responsibility as "the view that I am just as responsible for things that I allow or fail to prevent as for things I bring about, even when one of the causal links is the intervening act of another agent". ${ }^{23}$ The medical intervention in reproduction may reduce the risk of harm. When the woman is HIV positive, a supportive attitude by the medical staff may stimulate the woman to follow the recommendations that reduce the risk of vertical transmission of the infection to the child. In the case of an HIV infected man, the risk of horizontal transmission and indirectly of vertical infection can be reduced by stimulating the woman's ovaries, washing the sperm, and timing the ovulation before the insemination. Suppose that the risk of HIV transmission to a woman after unprotected intercourse is five per cent while the risk is reduced to zero when all precautions are taken. Suppose also that a number of these couples are practising unprotected intercourse in order to conceive. They very much prefer to use the safer medical method but the doctor refuses. This doctor would then be negatively responsible for the infection and death of a number of women and children. These women would not have been infected but for his refusal to provide treatment.

Is this a correct presentation of the situation? It could be argued that the doctor is not responsible for the infection of the women since it is their autonomous decision to have sex, knowing the risks of infection. Even when the couple tells him that if he refuses they will have unprotected intercourse, this is still their decision. The physician's refusal did not cause or provoke this. In order to determine whether the doctor is responsible and whether he should be blamed for the avoidable infections, one should determine whether he has a moral duty to provide treatment. The normative beliefs about the duty of the physician play an important role in the evaluation. Risk reduction and prevention of harm constitute an essential part of the obligations of the physician. For some authors, this duty only applies to the risk when the woman is already pregnant, that is when the high risk situation already exists. ${ }^{24}$ When the physician participates in the conception, he helps to increase the risk that he later should try to reduce. Auroux argues that it is shocking that medicine would restore a risk that was eliminated by nature. ${ }^{25}$ This argument only takes into account the risk for the future offspring, however, and ignores horizontal transmission. Moreover, elimination of risk for offspring applies only to infertile couples and it applies to all infertile couples and not only to HIV positive people. The only way to guarantee a zero risk is by not having children. The situation changes completely with fertile couples. Infertility treatment should be seen as an intervention to reduce the risk for the future offspring (and for the non-affected partner), just like the offer to use donor gametes when the parents are at high risk of transmitting a genetic disease. The French Minister of Health accepted the application of medically assisted reproduction for HIV positive couples, using this analogy. ${ }^{26}$

\section{CONCLUSION}

For the evaluation of the treatment performed by the physician, a distinction should be made between treatment aimed at risk reduction and treatment aimed at conception. In the case of a fertile couple, treatment is motivated by the wish to reduce harm for the future offspring and the uninfected partner. The physician's contribution to the 
conception is negligible since no help is needed to conceive. The effect of his actions is situated at the level of risk reduction. He cannot be blamed for the infected children that will be born despite his efforts. Moreover, risk reduction is part of the moral obligations of a physician. Given his prima facie obligation to act in the best interests of his patients, the physician has a duty to assist fertile HIV positive couples.

When the couple is infertile, the physician's causal contribution is significant and necessary. He inevitably intends to help the principals to have a child. The risk of transmission of the disease is not sufficient to condemn the parents for irresponsible behaviour. Since the parental project is morally acceptable, assistance by the physician with that project is also acceptable. He is responsible for the affected children (as he is for all children born with a handicap after his assistance) but neither the parents nor he can be blamed for recklessness. A physician should at least have the right to collaborate in the parental project of HIV positive infertile couples.

Research for this article was made possible by grant G.0065.00 from the Fund for Scientific Research, Flanders, Belgium.

\section{REFERENCES}

1 Hutton N. Health prospects for children born to HIV infected women. In: Faden RR, Kass NE, eds. HIV, AIDS, and childbearing: public policy, private lives. New York, Oxford: Oxford University Press, 1996:63-77.

2 Pennings G. Measuring the welfare of the child: in search of the appropriate evaluation principle. Hum Reprod 1999;14:1146-50.

3 Musoke PM, Mmiro FA. Prevention of HIV mother to child transmission: a review. AIDS Rev 2000;2:263-70.

4 Arras JD. AIDS and reproductive decisions: having children in fear and trembling. Milbank Q 1990;68:353-82.

5 Duff RA. Intention, agency, and criminal liability: philosophy of action and the criminal law. Oxford: Blackwell, 1990:142.

6 Buchanan A, Brock DW, Daniels N, et al. From chance to choice: genetics \& justice. Cambridge: Cambridge University Press, 2000:204-57.
7 Drapkin Lyerly A, Anderson J. Human immunodeficiency virus and assisted reproduction: reconsidering evidence, reframing ethics. Fertil Steril 2001;75:843-58

8 Glover J. Fertility and the family. London: Fourth Estate, 1989:49.

9 Novaes SB. Making decisions about someone else's offspring: geneticists and reproductive technology. In: Fortune M, Mendelsohn E, eds. The practices of human genetics. Dordrecht, Boston, London: Kluwer Academic, 1999: 169-84.

10 Savulescu J. Should doctors intentionally do less than the best? J Med Ethics 1999:25:121-6.

11 Emanuel EJ, Emanuel LL. Four models of the physician patient relationship. JAMA 1992;267:2221-6.

12 British Medical Association. Changing conceptions of motherhood: the practice of surrogacy in Britain. London: BMA, 1996:20.

13 Kadish S. A theory of complicity. In: Gavison R, ed. Issues in contemporary legal philosophy: the influence of H L A Hart. Oxford: Clarendon Press, 1987:287-303.

14 Feinberg J. The moral limits of the criminal law [vol 1: harm to others]. New York, Oxford: Oxford University Press, 1984:124.

15 Smith JR, Forster GE, Kitchen VS, et al. Infertility management in HIV positive couples: a dilemma. BMJ 1991;302:1447-50.

16 Olaitan A, Reid W, Mocroft A, et al. Infertility among human immunodeficiency virus positive women: incidence and treatment dilemmas. Hum Reprod 1996;11:2793-6.

17 Pellegrino E. The place of intention in the moral assessment of assisted suicide and active euthanasia. In: Beauchamp TL, ed. Intending death: the ethics of assisted suicide and euthanasia. Upper Saddle River, New Jersey: Prentice Hall, 1996:163-83.

18 Thorp JM, Wells SR, Bowes WA, et al. Integrity, abortion, and the prolife perinatologist. Hastings Cent Rep 1995;25:27-8.

19 Wertz DC, Fletcher JC. Fatal knowledge? Prenatal diagnosis and sex selection. Hastings Cent Rep 1989;19:21-7.

20 Moore MS. Causation and responsibility. In: Paul EF, Miller FD Jr, Paul J, eds. Responsibility. Cambridge: Cambridge University Press, 1999:1-51.

21 Frey RG. Some aspects of the doctrine of double effect. Can J Philos 1975;5:259-83.

22 Harris J. The value of life. London, NewYork: Routledge, 1985:29.

23 Williams B. A critique of utilitarianism. In: Smart JJC, Williams B, eds. Utilitarianism: for and against. New York: Cambridge University Press, 1973:94.

24 Spike J, Greenlaw J. Case study: ethics consultation. J Law Med Ethics 1994; 2:347-50.

25 Auroux M. Faut-il traiter l'infertilité chez les couples dont l'un des partenaires est séropositif? Fertil Contracept Sex 1999;27:118-20.

26 Nau JY. La procréation médicalement assistée s'ouvre aux couples porteurs du $\mathrm{VIH}$. Le Monde 2001 May 28. http://www.lemonde.fr/imprimer/article/ $0,6063,189997,00 \cdot \mathrm{html}$ (accessed 06 Oct 01). 